Utah State University

DigitalCommons@USU

$1-1-2015$

\title{
ALA Midwinter 2015: Issues in Resource Sharing and Implementing a Tool for Tracking Electronic-resource Outages
}

Robert Heaton

Utah State University

Follow this and additional works at: https://digitalcommons.usu.edu/lib_pubs

Part of the Library and Information Science Commons

\section{Recommended Citation}

ALA Midwinter 2015: Issues in resource sharing and implementing a tool for tracking electronic-resource outages. Journal of Electronic Resources Librarianship, 27 (2), 127- 132.

This Article is brought to you for free and open access by the Libraries at DigitalCommons@USU. It has been accepted for inclusion in Library Faculty \& Staff Publications by an authorized administrator of DigitalCommons@USU. For more information, please contact digitalcommons@usu.edu.

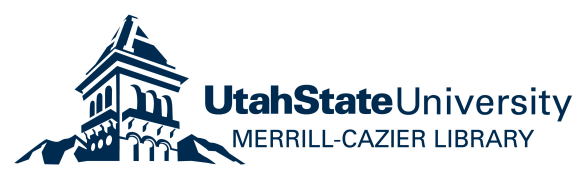


Running Head: ALA MIDWINTER 2015: ILL AND TROUBLESHOOTING

ALA Midwinter 2015: Issues in Resource Sharing and Implementing a Tool for Tracking Electronic-Resource Outages

Author Note: This is a preprint of an article whose final and definitive form has been published in the Journal of Electronic Resources Librarianship 2015, (CRobert Heaton; Journal of Electronic Resources Librarianship is available online at http://dx.doi.org/10.1080/1941126X.2015.1029425. 
Among many great sessions on electronic-resource management at ALA Midwinter in Chicago, two ALCTS Interest Group (IG) meetings covered relevant ideas in considerable depth. These were the Collection Management and Electronic Resources IG meeting, on the state of resource sharing of electronic resources, and the Electronic Resources IG meeting, on tracking e-resource outages in detail. The former was in the format of an open, guided discussion on many overlapping issues while the latter was an individual presentation followed by Q\&A.

\section{Problems, Opportunities, and Alternatives for Resource Sharing in the Digital Age}

Interest Group chair George Stachokas of Purdue University, with vice-chair Jennifer Bazeley of Miami University (Ohio), directed the ALCTS Collection Management and Electronic Resources IG meeting, which brought an impressive array of resource-sharing issues to the table for discussion. Mr. Stachokas ably introduced the topic by highlighting key distinctions between the print and digital worlds. For example, traditional interlibrary loan is essentially warehouse management, its materials are discovered through local and union catalogs, and it is governed by copyright law. In contrast, online resources are remotely discovered and accessed through multiple sources, their use and sharing are administered through systems that are deeply integrated into departments and processes outside of interlibrary loan, and any sharing is governed by contract law. Along with unsurprising data showing increased electronic-resource expenditures, it was also shown that while interlibrary borrowing by ARL libraries is trending slightly down, broader data sources show steady increases in fulfilled ILL requests and library expenditures on ILL and document delivery. Libraries continue to prioritize the sharing of resources in the digital age.

Mr. Stachokas went on to define some of the overlapping challenges and opportunities in the changing library ecosystem. These include:

- More users are discovering more content; users' needs are fluid and unpredictable 
- New business models exist, including providing access instead of developing (and sharing) collections

- $\quad$ License agreement could-but generally do not-promote expanded access

All of this is against a backdrop of slower growth of print collections for traditional sharing and, at least in some cases, shrinking ILL departments due to library automation. Given the above context, discussion was opened up around five key questions, which begin each of the sections below, followed by brief notes on the discussion that took place.

\section{Technical Infrastructure}

Question 1: Should libraries continue to maintain separate software systems for ILL/resource sharing or should these be integrated into the same tools used to manage other library materials, e.g., electronic resources?

In response to the first question, the repeated note was one of frustration with current systems. Specific pain points included the need to use multiple systems in a single workflow and the lack of key information (e.g., lending rights as stipulated in license agreements) at the point of need (i.e., fulfilling a loan request). A wise audience member moved the conversation toward productive action by suggesting that a library's culture can shift ahead of those limitations and focus on leveraging the benefits of existing tools. The Ex Libris Alma ERMS was mentioned for its integration with the larger ILS as was WorldCat Knowledge Base for its integration with ILLiad, but neither offered a complete solution. It was also mentioned that the general improvement of each tool may be a higher priority than the integration of multiple tools.

\section{Business Models}

Question 2: Should the exploration of new business models by resource sharing/ILL units be more closely coordinated with other library personnel? 
This question was framed by the example of a library's ILL unit experimenting with purchase on demand of print books, its e-resources unit experimenting with Elsevier transaction tokens, and its acquisitions unit experimenting with a patron-driven-acquisitions model for e-books. The first general response was that libraries need more data, particularly on users' means of discovery. A library's dual task is to expose content and to provide access to that content. Once the main channels for those activities are accounted for, the library can more effectively mold its staffing and workflows around those needs. This all presumes a high-level vision for the library's foray into programs and services, using data to make coordinated decisions. Another thread of discussion considered the possibilities for collaboration among departments in order to reduce duplication of efforts, which was covered more specifically in the next question.

\section{Cooperation among E-Resource and ILL Staff}

Question 3: What practical steps could be taken to improve the coordination between electronicresources-management and interlibrary-loan staff?

Mr. Stachokas specifically mentioned here the possibility of cross-consulting on license terms in order to negotiate favorable options for resource sharing, and several existing options were cited by attendees. One referred to the "view terms" field in the Serials Solutions 360 Resource Manager ERM tool, which allows the customized display of certain license terms. Others use online repositories of license metadata (in LibGuides or custom pages) to expose key terms to ILL staff as well as to users. And other third-party tools allow live reporting of data from management systems, but this is generally closed off from patron access. No clear "winner" emerged as a best practice in this area.

It was mentioned that decisions around exposing license terms should be based on the intended "consumption" of this information. The key use of it will also inform decisions on the negotiation process - whether to move to standardized language where possible, how to prioritize the fight for certain license terms, and whom to involve in negotiations. But the ideal system, it was agreed, would 
be structured around supporting the individual lending transaction, using a single system and providing the rich level of detail needed; some new technologies are moving toward such integrated access. In response to the prompt for practical steps, the discussion skirted around the general idea of opening up communication between e-resources and ILL staff and jointly making decisions where these would affect both units.

\section{Freely Available Electronic Resources}

Question 4: Should libraries add more freely available electronic resources to their "collections"?

The context for this question was that of access. In other words, if more effort goes toward curating high-quality resources for universal access, might there be less need for complex schemes of collecting and sharing? Approaches to this area varied considerably. Some libraries felt justified in opening up access wherever possible, turning on whole Open Access collections in A-Z journal lists, for example. Other attendees voiced a concern that it would be unwise to open the OA floodgates too wide because third-party support is usually lacking and makes troubleshooting difficult. At least one attendee's library follows the same procurement process with free resources as for paid ones, with faculty requests funneled through subject librarians for evaluation. And still others felt that their staff were efficient enough that fulfilling requests for freely available content did not represent an undue burden.

From the cloud of real concerns with providing access to free resources, Mr. Stachokas raised a potentially divisive but certainly incisive question: Is there a disconnect between libraries' promoting of Open Access publishing and their actual support of it?

\section{Administrative Organization}

Question 5: How should resource sharing be organized in contemporary academic libraries?

This final question reflects a longstanding dilemma that the addition of electronic-resource management complicates only slightly, which is where ILL might best fit into the organizational structure 
of a library. It was mentioned that resource-sharing units already house functions that are also performed by some other unit in the library; there are certainly a multitude of skills and processes there that overlap with those of Circulation, IT, Collection Development, Reference, and other areas. Someone suggested that shifting an organizational structure may not be worth the effort, in part because people find it hard to change how they do things. So if such a shift is attempted, decisions should be made with broad input and open communication through the transition. It was also agreed, first, that a professional-level librarian needs to be in the ILL department to train staff and make high-level decisions and, second, that the department's work will be the same no matter where it is located in the organizational chart.

\section{Conclusion}

This meeting focused productively on specific practices in resource sharing today and similarities and differences in how they are implemented at different institutions. The Interest Group will be meeting again at ALA Annual in San Francisco to discuss case studies of libraries' structural reconfigurations involving interlibrary-loan or resource-sharing departments.

\section{Planning Deliberate Processes for Managing E-Resource Troubleshooting Ticketing}

The ALCTS Electronic Resources IG, chaired by Jeannie Castro of the University of Houston, met for a presentation by Jennifer Wright of the University of Michigan Library's Electronic Access Unit, a four-member team responsible for coordinating the troubleshooting of e-resource access issues. Ms. Wright's presentation detailed some of their efforts to use a tool to track reported issues, as well as some of the refinements made to that tool and to the processes built around it. Troubleshooting is often a time-consuming process, and any ideas in this area can have a major impact on the work such a unit is able to accomplish.

\section{Systems}


As outlined in the presentation, a number of systems combine to form the University of Michigan Library's issue-tracking ecosystem. First, troubleshooting staff check a sample of links quarterly in the library's discovery product, Summon, but the variety and quantity of resources exposed there make it impossible to verify the accuracy of all links all the time. Online surveys administered through Qualtrics form a second system in their process: one form is available for users to report specific problems, and another is completed by service-desk staff. These are a key part of the process because the data reported from the survey tool includes the URL with the problem, the user's email address, and other specifics that make troubleshooting possible. Finally, the troubleshooting team interacts with tickets - and with library users - using a dedicated "workspace" in BMC Software's FootPrints ticketmanagement system.

The bulk of the presentation was dedicated to discussing the customization and ongoing use of this FootPrints troubleshooting workspace-at a conceptual rather than technical level. A commercially produced tool, FootPrints is used at many institutions of higher education (but not always by the library), and at Michigan many library units use their own workspaces to track patron interactions. As a single system for emailing individual patrons in connection with specific tickets, FootPrints helps facilitate communication within the library, allowing reference librarians, for example, to escalate reported problems to the troubleshooting team without losing any of the context of prior transactions. The presentation focused on the use of this tool during the period June 2013-June 2014 because although it was implemented earlier, substantial configuration changes were made to ensure they were capturing the right data.

\section{Issue Categories}

Any outage falls somewhere within a fairly detailed categorization scheme defined by the troubleshooting group (and helpfully provided to attendees as a handout):

- $\quad$ Bundled content 
- Configuration

- $\quad$ Proxy

- Violation/Breach

- Holdings

- Metadata

- $\quad$ OpenURL

- $\quad$ Scheduled maintenance

- $\quad$ Target content lacking

- $\quad$ Target site down

- Subscription

- $\quad$ Other

Electronic-resource management often involves jargon, and this is no exception. Brief definitions were given in the handout and are not reproduced here, but by way of example, the "bundled content" label refers to documents published containing multiple articles or entries. This is not a technical problem but rather a point of confusion for users. "Subscription" is used for tickets where the vendor does not register the institution's having a current subscription, e.g., as might happen due to a payment's being lost in the mail. Some categories are quite similar to one another but carry important distinctions. For example, "metadata" signifies a lack of descriptive metadata that is needed for an OpenURL request to resolve properly while "OpenURL" is used when the metadata is in place in the source database but the link resolver formats the request syntax improperly. Such labels are applied near the end of the troubleshooting process because the nature of the problem generally becomes clear as the resolution of it unfolds.

The apparent complexity of such a tagging system led to various issues that were resolved during the implementation and management of the FootPrints workspace. Troubleshooting staff quickly 
found that a controlled vocabulary was needed so that the above labels could be applied consistently, so the library's programmer built in a drop-down menu for applying them to tickets. Also in this vein, the categories themselves were altered, clarified, and added to in order to cope with staff's inconsistent understanding or application of them. On an ongoing basis, the troubleshooting team is cleaning up the repository of tickets. Received emails automatically generate tickets if not part of an existing conversation thread, so these are reviewed and deleted from the ticketing workspace. Policies are still being considered for how to handle exceptional cases, such as how long to wait for an individual-level (rather than system-wide) problem to be resolved before closing the associated ticket, but the infrastructure is largely in place and working well. The library's broader use of FootPrints made buy-in easier than it might be for an outside system, so the troubleshooting team's work was mostly dedicated to fine-tuning their particular implementation.

\section{Applications of Reported Data}

With their ticketing system in place, the library could generate customized reports as a way of using the system's data. Ms. Wright mentioned that having concrete data adds considerable weight to an argument for a course of action. And the data is substantial: they recorded around 1,600 outages in the 13-month period of June 2013-June 2014. Around $42 \%$ of these were deemed to be the fault of vendors. One-quarter of problems were due to content not being available on a vendor's site, and some data was available on the responsiveness of vendors to such reports. Vendor-related data could be further broken down by problem type, so EBSCO and ProQuest, for example, could be (roughly) compared on the basis of the quality of their metadata passed through to a link resolver, with the obvious benefit of using this data to support purchasing and renewal decisions. Even when no purchase is involved, as with Open Access repositories, having outage data helps inform decisions on the nature and extent of support the library will provide for these resources. At present, though, much of the use of 
the data is effectively disconnected from the gathering of it. For example, public-services staff maintain front-line contact with users and can rely on past tickets for guidance in resolving new problem reports.

\section{Conclusion}

Ultimately, the costs of both the FootPrints software and an in-house programmer may make it unfeasible for many libraries to implement this same system, but the principles and processes described in this session are still instructive. Honest discussion of problems encountered and the time required to set up and use such a system showed that it was possible and worthwhile-with local adaptations-and attendees seemed eager to explore something similar at their institutions. E-resource troubleshooting will continue to be an ambiguous and confusing enterprise, and a better grasp on existing problems and their resolution can help libraries identify trends and save time. 